\title{
Determination of Acrylamide in Portuguese Bread by UPLC- MS/MS: Metrological and Chemometric tools
}

\author{
Susana Jesus ${ }^{1,2}$, Inês Delgado ${ }^{1,3}$, Andreia Rego ${ }^{1,2}$, Carlos Brandão ${ }^{4}$, Rui Galhano dos Santos ${ }^{2}$, João \\ Bordado $^{2}$, Isabel Castanheira ${ }^{1}$ \\ ${ }^{1}$ Departamento de Alimentação e Nutrição, Instituto Nacional de Saúde Doutor Ricardo Jorge, I.P., Lisboa, Portugal \\ ${ }^{2}$ CERENA - Centre for Natural Resources and the Environment, Universidade Técnica de Lisboa, Instituito Superior Técnico, Lisboa, Portugal \\ ${ }^{3}$ Chemical Engineering Department, Instituto Superior Técnico, Lisboa, Portugal \\ ${ }^{4}$ Escola Superior de Hotelaria e Turismo do Estoril, Estoril, Portugal
}

\section{ABSTRACT}

Acrylamide (AA) is known for its potential health hazards and it is present in processed potatoes, coffee, and bread. Wheat is still the most important cereal for bread making, however, the interest in its substitution by other grains is growing due to the consumer demand for novels and healthy foods, like oat and rye flour. The aim of this study was to analyze the AA content of confectioned bread in fifty-four different pastries and make an association of acrylamide contents and the place of production to identify the quality of the flour used. There was a wide variability in AA levels among different breads and within different bread varieties. The median of AA values was $787 \mu \mathrm{g} / \mathrm{kg}$ for whole grain bread, $783 \mu \mathrm{g} / \mathrm{kg}$ for oat bread and $253 \mu \mathrm{g} / \mathrm{kg}$ in rye bread.

With the cluster analysis, it was possible to conclude that besides the factors like baking temperature-time and fermentation time which affects AA formation in bread products, several other parameters such as the formulation, flour quality and the varieties of processing techniques, among others, play a crucial role in the AA formation.

\section{Section: RESEARCH PAPER}

Keywords: acrylamide; occurrence; UPLC-MS; EFSA

Citation: Susana Jesus, Inês Delgado, Andreia Rego, Carlos Brandão, Rui Galhano dos Santos, João Bordado, Isabel Castanheira, Determination of Acrylamide in Portuguese Bread by UPLC-MS/MS: Metrological and Chemometric tools, Acta IMEKO, vol. 7, no. 2, article 17, June 2018, identifier: IMEKO-ACTA-07 (2018)-02-17

Section Editor: Claudia Zoani, Italian National Agency for New Technologies, Energy and Sustainable Economic Development affiliation, Rome, Italy Received February 16, 2017; In final form April 6, 2018; Published June 2018

Copyright: $\odot 2018$ IMEKO. This is an open-access article distributed under the terms of the Creative Commons Attribution 3.0 License, which permits unrestricted use, distribution, and reproduction in any medium, provided the original author and source are credited

Funding: This work was supported by ELEMENTARIA-2013DAN850 project

Corresponding author: isabel.castanheira@insa.min-saude.pt

\section{INTRODUCTION}

Acrylamide (AA) is mainly used as a monomer in the polymerization reaction of polyacrylamide. It is present in cooked foods and cigarette smoke; nevertheless, the occurrence of acrylamide in foods was only firstly reported in 2002 [1], [2].

In 1994, the International Agency for Research on Cancer (IARC) classified acrylamide as a carcinogen in animals and probably to humans (Group 2A)[1], [3]-[7]. Also, the European Commission in 2002 classified this compound as category 2 for carcinogenicity and category 2 for mutagen [8]. The harmful effect of such compound on humans was later confirmed, and nowadays the acrylamide is, in fact, considered a neurotoxic substance. In people overexposed to such compound, the peripheral nervous system can be impaired as well as the central nervous one [2], [9]. Besides that, the acrylamide metabolism is considered genotoxic [10]-[17]. After being absorbed and distributed by cells, a process of oxidation by cytochrome P450 $2 \mathrm{E} 1$ is initiated, leading to the transformation of acrylamide in glycidamide, a genotoxic agent, which reacts with the DNA. The reactional products can originate DNA adducts that are associated with cell damage. Nevertheless, the untransformed acrylamide and its metabolites are eliminated by urine [10], [11], [15], [16], [18]. 
There are three pathways for the formation of acrylamide in processed foods [19]-[20]. One is the thermal decomposition of lipids which results in a significant amount of acrolein. Afterward, the oxidation of acrolein generates acrylic acid that in the presence of ammonia conducts to the formation of acrylamide. Another pathway is carnosine pyrolysis, which liberates acrylic acid. As in the case of the lipid route, the acrylic acid originates acrylamide in the presence of ammonia. Finally, the main route for acrylamide formation in foods is a consequence of the Maillard reaction which involves a free amino acid (asparagine) and reducing sugars. The reaction of these precursors results in a Schiff base which undergoes through decarboxylation to afford 5-1-oxazolidine. Subsequently, the decarboxylated product could decompose either to acrylamide, 3-oxopropanamide or 3aminopropionamide (3-APA). The excessive sugar amount could also be responsible for the formation of acrylamide (Figure 1) [4]. M. Cengiz, C. Gündüz reported acrylamide levels of $225 \mu \mathrm{g} / \mathrm{kg}$ and $495 \mu \mathrm{g} / \mathrm{kg}$ in bread and cookies, respectively [21]. In Finland, S. Eerda, K. Hollebekkers, Hallikainen A. and $\mathrm{K}$. Peltonen obtained acrylamide levels in bread and sweet biscuits of $645 \mu \mathrm{g} / \mathrm{kg}$ and $310 \mu \mathrm{g} / \mathrm{kg}$ [22], respectively, but a study in Belgium showed lower results in bread with $34 \mu \mathrm{g} / \mathrm{kg}$ and biscuits with $154 \mu \mathrm{g} / \mathrm{kg}$ [23]. Dietary acrylamide exposure of population is mainly dependent on the contaminant amounts in foodstuffs.

For the risk supervision of acrylamide, it is necessary to identify and characterize it. For non-neoplastic, Benchmark dose (BMDL10) is $0.43 \mathrm{mg} / \mathrm{kg}$ b.w. per day, but for neoplastic effects, it is $0.17 \mathrm{~g} / \mathrm{kg}$ b.w. per day [25].

In this year, the European Commission published a regulation about the acrylamide mitigation measures and benchmark levels in foodstuffs [26]. This regulation establishes mitigation approaches for foodstuff, considering 3 phases, agronomical, product design and processing. However, until this date, EFSA did not set maximum limits but stated indicative values for various food groups such as cereals (Table 1) [24]. Occurrence data is required to support EFSA decisions since the data correlation between acrylamide intake and biological biomarkers of exposure become crucial to evaluate the dietary exposure: it is therefore important to accurately assess the level of acrylamide in various processed food.

To this date, in Portugal as in other European countries,

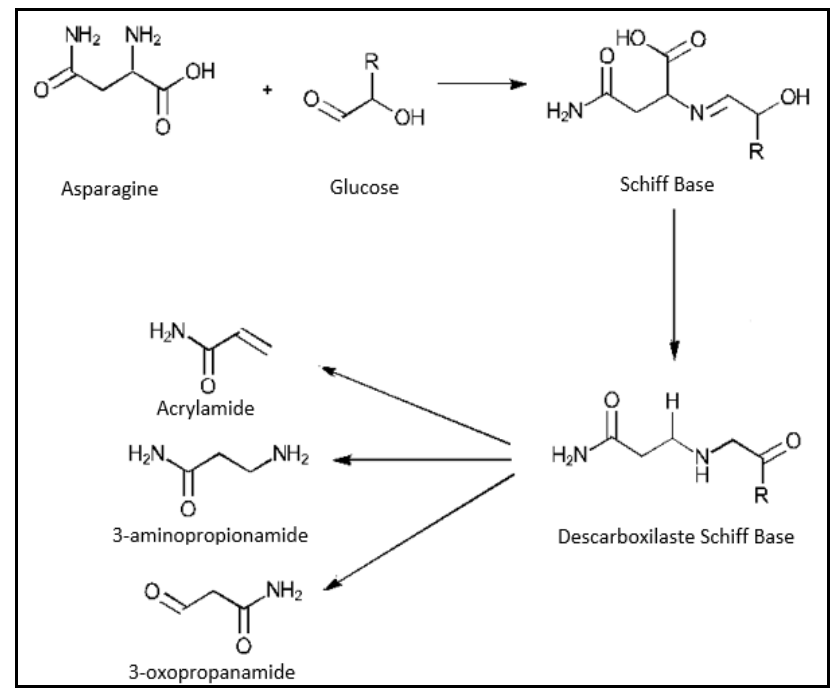

Figure 1. Acrylamide formation of the Maillard Reaction.
Table 1. Indicative values set by European Commission for acrylamide content in cereal-based foods [24].

\begin{tabular}{lc}
\hline \multicolumn{1}{c}{ Foodstuff } & $\begin{array}{c}\text { Indicative } \\
\text { Values } \\
(\boldsymbol{\mu g} / \mathbf{k g})\end{array}$ \\
\hline Soft bread & 80 \\
a) Wheat based bread & 150 \\
b) Soft bread other than wheat based bread & \\
\hline Breakfast cereals & 400 \\
- Bran products and whole grain cereals & 300 \\
- Wheat and rye-based products & 200 \\
- Maize, oat spelt, barley and rice based products & 500 \\
\hline - Biscuits and wafers & 500 \\
- Crackers & 450 \\
- Crispbread & 1000 \\
- Gingerbread & 500 \\
\hline - Products similar & 200 \\
\hline Biscuits and rusks for infants and young children & 50 \\
\hline Processed cereal-based foods for infants and young & \\
\hline children & \\
\hline
\end{tabular}

occurrence studies in cereal group are scarce. Therefore, the aim of this study is to assess the levels of acrylamide in bread confectioned in several pastries and make an association of acrylamide contents with the place of production to further identify the quality of flour. These values are discussed and compared with those available in others European Countries.

\section{MATERIALS AND METHODS}

\subsection{Sampling and sample preparation}

Bread varieties were collected randomly from 54 industrial producers located in the district of Lisbon. Producers were asked about dough and bread preparation. The sampling plan is present in Table 2. Samples were analyzed as pool composed of 10 breads from the same producer.

\subsection{Dough and bread preparation}

The bread products collected were further categorized according to the flour: rye bread, oat bread and whole grain bread (bread with wheat flour and others in minor quantity). The time and temperature of the baking process did not vary between producers, ranging from $190{ }^{\circ} \mathrm{C}$ to $200{ }^{\circ} \mathrm{C}$. However, no information is available about either all ingredients used in recipe or the fermentation step.

\subsection{Reagents, chemical standards and materials AA analysis}

For this study, the following reagents were used: Acetonitrile (Merck gradient grid is liquid chromatography), formic acid (Group Carlo Erba Reagents, 99\% for analysis) Methanol (Merck, hypergrade for LC-MS) and ultrapure type 1 water (captured from a Milli-Q water purification system).

The standard used was the standard of acrylamide (99\%) Dr. Ehrenstorfer $\mathrm{GmbH}$ ). For the homogenization of samples, a Knife Mill Grindomix GM 200 was used. In the extraction of the compound to be analyzed in this study, an Eppendorf

Table 2. Sampling Plan applied in this study.

\begin{tabular}{cccc}
\hline Species & No Producer & $\begin{array}{c}\text { Number of } \\
\text { collected samples }\end{array}$ & $\begin{array}{c}\text { Number of } \\
\text { pools }\end{array}$ \\
\hline Oat & 23 & 230 & 23 \\
\hline Rye & 24 & 240 & 24 \\
\hline Mixture & 7 & 70 & 7 \\
\hline Total & 54 & & \\
\hline
\end{tabular}


centrifuge $5804 \mathrm{R}$, a vortex shaker type stirrer, a Kline stirrer and SPE columns (BondElut plexa, $6 \mathrm{~mL}, 200 \mathrm{mg}$ ) were used. In the identification and quantification of acrylamide the ultraefficient liquid chromatograph (ACQUITY UPLC) was used and the analytical column ACQUITY UPLC BEH C (18, 1.7 $\mu \mathrm{m}, 2.1 \times 150 \mathrm{~m})$ was obtained from Waters.

\subsection{Acrylamide extraction}

Bread was immediately prepared after the reception in the laboratory. Each sample was milled separately using a highspeed grinder (Knife mill GRINDOMIX GM), homogenized and stored in vacuum bags. $2 \mathrm{~g}$ of homogenized sample were weighed into a centrifuge tube, and $20 \mathrm{ml}$ water/ formic acid $(0.1 \%)$ was added. The sample was stirred in a vortex for 2 minutes and then in an oscillating shaker for $30 \mathrm{~min}$ at 70 oscillations per minute. Then, it was centrifuged at 10,000 rpm for 15 minutes.

Oasis HLB SPE cartridges (Waters) were conditioned with $3.5 \mathrm{ml}$ of methanol and equilibrated with $3.5 \mathrm{ml}$ of acidified water. $1.5 \mathrm{ml}$ of the sample were loaded and eluted with $3 \mathrm{ml}$ of acidified water to a flask of $10 \mathrm{ml}$, and the volume was completed with acidified water.

All samples were prepared and analyzed as three replicates. The results are expressed as mean and standard deviation.

\subsection{LC-MS/MS analysis}

Analysis was carried out in an Ultra Performance Liquid Chromatography coupled to a mass spectrometry (UPLCMS/MS) with electrospray ionization source (ESI). The method was operated using an isocratic elution with $90 \%$ water and $10 \%$ acetonitrile at a flow rate of $0.2 \mathrm{ml} / \mathrm{min}$. Retention and separation of acrylamide were achieved in a UPLC BEH C18 column $(2.1 \times 50 \mathrm{~mm})$ with 3 minutes of analysis and a retention time of 0.84 minutes. The UPLC-MS/MS was operated in the positive ion electrospray at the following conditions: capillary voltage of $3 \mathrm{kV}$, cone voltage $29 \mathrm{~V}$, source temperature $120{ }^{\circ} \mathrm{C}$, desolvation gas temperature $350{ }^{\circ} \mathrm{C}$, desolvation gas flow of $5 \mathrm{l} / \mathrm{hr}$, cone gas flow at $30 \mathrm{l} / \mathrm{hr}$ and the pressure of the collision gas was $3 \times 10^{-3}$ mbar.

\subsection{Quality Assurance}

The laboratory technical competence needed to carry out the acrylamide assay was provided by ISO/IEC NP 17025:2005.

Equipments used during experiments were calibrated according to approved calibration procedures and external standards traceable to national measurements standard, when available. All volumetric glassware belongs to Class A.

Certified reference material ERM -BD273 (toasted bread powder) was purchased from IRMM and used as a quality control of the method. The laboratory has participated in several PT schemes launched by accredited provider FAPAS to guarantee the laboratory performance. The performance of laboratory was expressed by the z-score, expressing the difference between the laboratory value and target value.

\subsection{Statistical analysis}

Statistical analysis was performed using Statistica 13 software (Statsoft Ibérica, Lisboa, Portugal). Data were expressed as mean and standard deviation. One-way analysis of variance (one-way ANOVA) was carried out in order to determine significant differences $(p<0.05)$ between data.

To make an association between acrylamide content in bread and the producer's recipe the obtained data were analyzed by multivariate hierarchical cluster analysis by linkage Ward's method. The distance between samples was calculated using Euclidean Distances.

\section{RESULTS AND DISCUSSION}

In this study, accuracy was assessed through certified reference material (ERM-BD273 toasted bread, certified value: $425 \pm 29 \mathrm{ng} / \mathrm{g}$ ) where the obtained analytical values are within $95 \%$ of the confidence level of certified value. Laboratory performance was demonstrated by participation in adequate PT Schemes, T3067 (Biscuit (cookie)) and T3059 (Biscuit (cookie)). In these assays, results were rated as satisfactory in all schemes. These results demonstrated the adequacy of the analytical procedure for acrylamide quantification.

The present study focused on Portuguese bread in common commercial market. A total of 54 bread samples divided into 3 groups (oat bread, rye bread, and whole grain bread) were analyzed for acrylamide concentration.

The occurrence data is shown in Tables 3, 4, and 5. In general, the acrylamide level in bread ranged between 60 and $1273 \mu \mathrm{g} / \mathrm{kg}$ depending on the bread types. The acrylamide concentrations in all bread types were order from high to low as whole grain bread $(786,86 \mu \mathrm{g} / \mathrm{kg})>$ oat bread $(783,00 \mu \mathrm{g} / \mathrm{kg})>$ rye bread $(252,90 \mu \mathrm{g} / \mathrm{kg})$. These results revealed high variation in acrylamide amount in different bread types, suggesting that differences in the so-called bread road-map, including types and quality of raw materials, formulations, baking methods can affect the acrylamide formation in bread.

In the whole grain bread was observed a median of 786,86 $\mu \mathrm{g} / \mathrm{kg}$ (Table 3). However, there were two samples (producer 1 and 3) in the range of 200 and $600 \mu \mathrm{g} / \mathrm{kg}$ and three samples higher than $900 \mu \mathrm{g} / \mathrm{kg}$. Once this type of bread had a high percentage of wheat flour, the differences in acrylamide levels can be attributed to the fact that this bread may have various levels of some fractions of wheat, such as germ and bran, which contain high levels of the main precursor (asparagine) for the acrylamide formation in bread [27].

Relatively to the oat bread (Table 4), it was found a median of $783 \mu \mathrm{g} / \mathrm{kg}$ and a maximum level of $1258 \mu \mathrm{g} / \mathrm{kg}$, results similar to the whole grain bread. Nevertheless, the producers $13,19,22,23$ and 51 confectioned bread with acrylamide range between 200 and $600 \mu \mathrm{g} / \mathrm{kg}$. Also, breads with acrylamide amount in the range of $600 \mu \mathrm{g} / \mathrm{kg}$ and $900 \mu \mathrm{g} / \mathrm{kg}$ were observed. On the other hand, the bread from producers 16 and 53 were below the $200 \mu \mathrm{g} / \mathrm{kg}$ level of this contaminant. The variation among results may be justified through the differences in oat flour brands because the composition of acrylamide

Table 3. Acrylamide levels in whole grain bread collected in several bakeries.

\begin{tabular}{cc}
\hline Producer & Acrylamide $(\mu \mathrm{g} / \mathrm{kg})$ \\
\hline 1 & $328.78 \pm 3.14$ \\
\hline 2 & $786.86 \pm 2.24$ \\
\hline 3 & $247.50 \pm 18.02$ \\
\hline 4 & $1159.66 \pm 5.38$ \\
\hline 5 & $1235.80 \pm 52.30$ \\
\hline 7 & $741.18 \pm 35.26$ \\
\hline
\end{tabular}


Table 4. Acrylamide levels in oat bread collected in several bakeries.

\begin{tabular}{|c|c|}
\hline Producer & Acrylamide $(\mu \mathrm{g} / \mathrm{kg})$ \\
\hline 13 & $269.40 \pm 5.22$ \\
\hline 14 & $1182.42 \pm 14.06$ \\
\hline 15 & $834.50 \pm 18.48$ \\
\hline 16 & $59.94 \pm 4.02$ \\
\hline 17 & $807.88 \pm 2.06$ \\
\hline 18 & $715.66 \pm 2.30$ \\
\hline 19 & $344.62 \pm 12.44$ \\
\hline 20 & $937.32 \pm 15.12$ \\
\hline 21 & $1105.38 \pm 23.56$ \\
\hline 22 & $546.18 \pm 2.98$ \\
\hline 23 & $579.96 \pm 7.60$ \\
\hline 24 & $1273.10 \pm 28.92$ \\
\hline 25 & $783.38 \pm 17.30$ \\
\hline 26 & $1208.28 \pm 48.20$ \\
\hline 27 & $851.10 \pm 5.92$ \\
\hline 28 & $1168.96 \pm 69.48$ \\
\hline 29 & $843.38 \pm 10.26$ \\
\hline 30 & $723.56 \pm 9.26$ \\
\hline 31 & $1259.00 \pm 11.66$ \\
\hline 51 & $387.82 \pm 26.88$ \\
\hline 52 & $195.42 \pm 4.76$ \\
\hline 53 & $119.70 \pm 4.14$ \\
\hline 54 & $749.58 \pm 47.10$ \\
\hline
\end{tabular}

precursors in flours are influenced by cultivars, year to year variations, harvest period, climate and soil composition [28].

In Table 5 , the rye bread had a median of $252,90 \mu \mathrm{g} / \mathrm{kg}$ and a maximum of $751 \mu \mathrm{g} / \mathrm{kg}$. Most samples were below 600 $\mu \mathrm{g} / \mathrm{kg}$, even so, acrylamide levels lower than $200 \mu \mathrm{g} / \mathrm{kg}$ were achieved by producers 36, 44, 48, 49, 50. These differences between acrylamide levels in rye bread can indicate that there is a difference in the asparagine content among the varieties of rye flours used by the producers.

As mentioned earlier, the acrylamide indicative value set by the European Commission for soft bread other than wheatbased bread was $150 \mu \mathrm{g} / \mathrm{kg}$ [24]. Some of the oat and rye bread results were around this value, namely from producers 53, 16, 50, 49, 48, 44 and 36 .

In 2009, EFSA reported a maximum level of acrylamide in bread group around $2430 \mu \mathrm{g} / \mathrm{kg}$ and in 2011 a maximum value of $2565 \mu \mathrm{g} / \mathrm{kg}$ and $910 \mu \mathrm{g} / \mathrm{kg}$ for bread non-specified and soft bred, respectively [29], [30]. The results obtained were lower than the occurrence levels of acrylamide reported by EFSA. More recently, based on analytical results from a total of 24 European Countries and six associations, EFSA reported maximum levels of acrylamide in unspecified soft bread around
Table 5. Acrylamide levels in rye bread collected in several bakeries.

\begin{tabular}{|c|c|}
\hline Producer & Acrylamide $(\mu \mathrm{g} / \mathrm{kg})$ \\
\hline 8 & $536.08 \pm 44.48$ \\
\hline 9 & $638.34 \pm 23.54$ \\
\hline 10 & $505.98 \pm 2.28$ \\
\hline 11 & $712.96 \pm 65.94$ \\
\hline 12 & $645.94 \pm 25.72$ \\
\hline 32 & $749.58 \pm 47.10$ \\
\hline 33 & $325.96 \pm 6.22$ \\
\hline 34 & $209.54 \pm 14.18$ \\
\hline 35 & $751.28 \pm 35.36$ \\
\hline 36 & $168.32 \pm 12.92$ \\
\hline 37 & $319.38 \pm 10.16$ \\
\hline 38 & $368.44 \pm 9.20$ \\
\hline 39 & $205.44 \pm 18.36$ \\
\hline 40 & $252.82 \pm 13.58$ \\
\hline 41 & $278.30 \pm 20.28$ \\
\hline 42 & $210.72 \pm 13.16$ \\
\hline 43 & $216.22 \pm 17.24$ \\
\hline 44 & $161.98 \pm 6.78$ \\
\hline 45 & $252.96 \pm 21.30$ \\
\hline 46 & $204.84 \pm 16.54$ \\
\hline 47 & $201.46 \pm 13.14$ \\
\hline 48 & $160.38 \pm 12.70$ \\
\hline 49 & $176.86 \pm 16.56$ \\
\hline 50 & $159.72 \pm 5.80$ \\
\hline
\end{tabular}

$141 \mu \mathrm{g} / \mathrm{kg}$, which is similar to bread samples analyzed from the producers 16, 53, 50, 48, 49, 36 and 44 [25]. Nevertheless, EFSA reported occurrence values for pumpernickel (rye bread) with a maximum of $245 \mu \mathrm{g} / \mathrm{kg}$ [25]. The majority of bread analyzed, 13 out of 24 , contained lower levels of acrylamide which may be explained by the difference between rye bread recipe in Portugal (flour mixture) and the pumpernickel (rye flour).

In the literature, Meghavarnam et al evaluated bread samples from the local market in India, obtaining a range between 1210 - $1365 \mu \mathrm{g} / \mathrm{kg}$ [31]. Similar results were achieved by European Commission in 2007 in bread and toast samples, $1987 \mu \mathrm{g} / \mathrm{kg}$ [32]. All the bread samples collected and analyzed in this work were below the maximum value of Meghavarnam et al and Wenzl studies.

Furthermore, the study published by Krishnakumar and Visvanathan reported a high variability of acrylamide concentration in bread group, $<10-3200 \mu \mathrm{g} / \mathrm{kg}$ [2]. Also, in this case, the results obtained in the three types of bread were lower than $3200 \mu \mathrm{g} / \mathrm{kg}$. 
On the other hand, other authors had observed minor levels of acrylamide in bread. Normandi et al analyzed the acrylamide concentration in Canadian bread and found a maximum value of $107 \mathrm{ng} / \mathrm{g}$. Also, in bread from Syria and Iran, similar results were achieved, $119-263 \mu \mathrm{g} / \mathrm{kg}$ and $166-290 \mu \mathrm{g} / \mathrm{kg}$, respectively [33] [34]. These levels are identical to the results observed in the bakeries $3,13,34,36,39,40,41,42,43,44,45$, 46, 47, 48, 49, 50, 52 and 53 .

In a higher range, Pacetti et al obtained an acrylamide content between $102-594 \mu \mathrm{g} / \mathrm{kg}$, which is higher than more than half of the bread samples (producers 1, 3, 8, 10, 13, 19, 22, $23,33,34,36,37,38,39,40,41,42,43,44,45,46,47,48,49$, 50, 52 and 53) [35]. Moreover, Gündüz et al analyzed bread types from Turkey and obtained a maximum of $695 \mu \mathrm{g} / \mathrm{kg}$ for all bread types. In this study, most of the bread samples were below this value. Gündüz et al also reported values for rye bread with a range of $209-624 \mu \mathrm{g} / \mathrm{kg}$, which is higher than the rye bread levels shown in the present work [36].

To study the relationship between the acrylamide levels and the recipe of producers, a cluster analysis was performed.

The results of the cluster analysis (Figure 2) in the present study are derived from the tree clustering analysis.

The hierarchical tree observed in Figure 2 provides a key to understand the relation between the bread samples and the producers.

It was possible to identify the presence of 5 major clusters. The first cluster grouped the bread samples $(4,5,7,14,21,24$, 26, 28 and 31) with the highest values, 1105.38 to 1273.10 $\mu \mathrm{g} / \mathrm{kg}$, where two types of bread, oat, and whole grain bread were included. These results can indicate that the oat bread producers of 14, 21, 24, 24, 26, 28 and 31 used flours with a similar amount of asparagine. Relatively to the whole grain bread, producers can be grouped with respect to the similarity of cooking phase. Nevertheless, the relation between these two types of bread can be explained by various reasons, such as the addition of other ingredients in the whole grain bread that influences the formation of acrylamide.

Most samples identified in the second cluster were from rye bread producers $(8,9,10,12,22$ and 23). In this cluster, the acrylamide content varies between 505.98 and $645.94 \mu \mathrm{g} / \mathrm{kg}$. The similarity of the results observed among the rye bread producers suggests that the flour and the cooking method were identical. In the case of oat bread producers (bakeries 22 and 23) included in this cluster, the similar results can be related to the asparagine content in oat flours.

Cluster 3 included the three varieties of bread $(2,6,11,15$, $17,18,20,25,27,29,30,32,35,54)$, but mostly oat bread, where the values are among 712.96 and $937.32 \mu \mathrm{g} / \mathrm{kg}$. In this

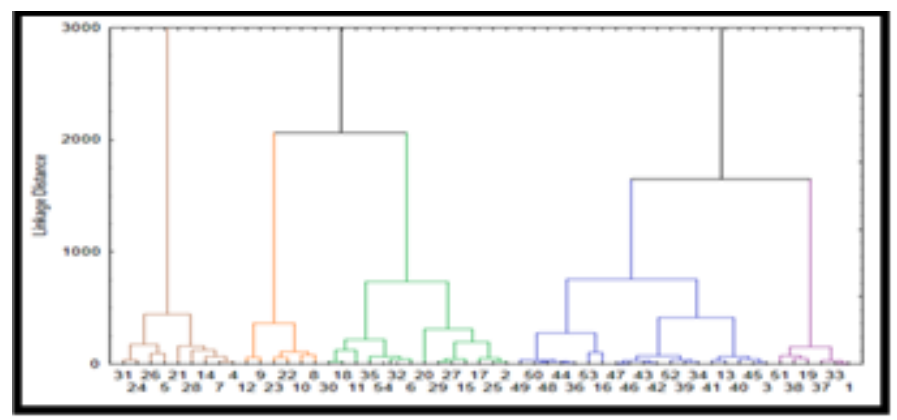

Figure 2. The relation between acrylamide formation and producer. Dendrogram grouped places in 5 clusters. cluster, the oat bread values are lower than in cluster 1 , which can be related to the lower asparagine content of the varieties of oat flour. The two bakeries that produce whole grain bread should have a large amount of oat flour than wheat flour because the values are close to the oat bread.

Cluster 4 was represented mostly by rye bread $(3,13,16,34$, $36,39,40,41,42,43,44,45,46,47,48,49,50,52$ and 53). In this group, the values of acrylamide are between 59.94 and $269.40 \mu \mathrm{g} / \mathrm{kg}$, which corresponds to the lowest values of acrylamide in general. To obtain the lowest value the producer may have used flour with low quantity of asparagine, but these results could also be caused by the cook confection, like the use of a high fermentation time.

The cluster 5 grouped the three varieties of bread analyzed in this study $(1,19,33,37,38,51)$, where the rye bread producers stand out. The acrylamide levels were between 319.38 and $387.82 \mu \mathrm{g} / \mathrm{kg}$, which represented the average values obtained from bread samples.

The cluster analysis grouped the samples with similar values of acrylamide, which allowed a preliminary conclusion about the association of acrylamide contents with the bread producers. However, there are many factors, such as crop management, fermentation process, that need more attention to comprehend the high variability of the results.

\section{CONCLUSIONS}

Food is an important source of exposure to acrylamide of the population. Thus, in this study the acrylamide content in confectioned bread in several bakeries was determined and an association of acrylamide contents with the producers was made. The applied Quality Control procedures, framed by ISO 17025 requirements, demonstrated adequacy to guarantee the reliability of the obtained data. Hierarchical cluster analysis, as applied to the data acquired from the content of acrylamide in three variants of bread, was useful. Chemometric tools allowed identifying factors that could influence the acrylamide formation.

This work is aligned with those that advocate the need for national data to estimate the real dietary exposure to acrylamide.

\section{PUBLICATION}

Part of this work was presented at $2^{\text {nd }}$ IMEKOFOODS, Benevento 2016, as poster.

\section{ACKNOWLEDGEMENT}

MISAGE project (LISBOA-01-0145-FEDER-024172). This project has received financial support from the Fundação para a Ciência e a Tecnologia (FCT), Portugal.

\section{REFERENCES}

[1] R. C. Alves, C. Soares, S. Fernandes, and M. Oliveira, Acrylamide in espresso coffee: Influence of species, roast degree and brew length, Food Chem., vol. 119, (2010), pp. 929-934.

[2] T. Krishnakumar and R. Visvanathan, Acrylamide in Food Products: A Review, J. Food Process. Technol., vol. 5, (2014).

[3] N. Muttucumaru et al., Acrylamide-forming potential of potatoes grown at different locations, and the ratio of free asparagine to reducing sugars at which free asparagine becomes a limiting factor for acrylamide formation, Food Chem., vol. 220, (2016), pp. 76-86.

[4] E. L. De Paola, G. Montevecchi, F. Masino, D. Garbini, M. 
Barbanera, and A. Antonelli, Determination of acrylamide in dried fruits and edible seeds using QuEChERS extraction and LC separation with MS detection, Food Chemistry, vol. 217, (2017), pp. 191-195.

[5] F. Xu, M. J. Oruna-Concha, and J. S. Elmore, The use of asparaginase to reduce acrylamide levels in cooked food, Food Chem., vol. 210, (2016), pp. 163-171.

[6] IARC. Monographs on the evaluation of carcinogenic risks to humans: some industrial chemicals. No. 60, (1994).

[7] JECFA. Safety evaluation of certain contaminants in food. Acrylamide In: 72nd meeting of the Joint FAO/WHO Expert Committee on Food Additives (JECFA). FAO JECFA Monograph 8: 1 -151, (2011).

[8] European Commission. "Opinion of the scientific committee on food on new findings regarding the presence of acrylamide in food, (2002).

[9] R. M. LoPachin, The changing view of acrylamide neurotoxicity, Neurotoxicology, vol. 25, (2004), pp. 617-630.

[10] S. Bandarra, A. Fernandes, I. Magro, P. Guerreiro, M. Pingarilho, M. Churchwell, O. Gil, I. Batiniz-Hberle, S. Gonçalves, J. Rueff, J. Miranda, M. Marques, F. Beland, M. Castro, J. Gaspar, N. Oliveira, Mechanistic insights into the cytotoxicity and genotoxicity induced by glycidamide in human mammary cells, Mutagenesis, vol. 28, (2013), pp. 721-729.

[11] A. Carere, Genotoxicity and carcinogenicity of acrylamide: A critical review, Ann. Ist. Super. Sanita, vol. 42, (2006), pp. 144 155.

[12] A. Besaratinia and G. P. Pfeifer, Genotoxicity of Acrylamide and Glycidamide, JNCI J. Natl. Cancer Inst., vol. 96, 2004, pp. 1023 1029.

[13] H. Mojska, I. Gielecińska, L. Szponar, M. Ottarzewiske, Estimation of the dietary acrylamide exposure of the Polish population, vol 48, (2010), pp. 2090-2096.

[14] W. Parzefall, Minireview on the toxicity of dietary acrylamide, Food Chem. Toxicol., vol. 46, (2008), pp. 1360-1364.

[15] E. Capuano and V. Fogliano, Acrylamide and 5hydroxymethylfurfural (HMF): A review on metabolism, toxicity, occurrence in food and mitigation strategies, LWT - Food Sci. Technol., vol. 44, (2011), pp. 793-810.

[16] M. Obón-Santacana et al., Dietary intake of acrylamide and endometrial cancer risk in the European Prospective Investigation into Cancer and Nutrition cohort, Br. J. Cancer, vol. 111, (2014), pp. 987-97.

[17] A. Besaratinia and G. P. Pfeifer, A review of mechanisms of acrylamide carcinogenicity, Carcinogenesis, vol. 28, (2007), pp. 519-528.

[18] P. Erkekoglu, T. Baydar, Acrylamide neurotoxicity, Nutr Neurosci. Vol.17, (2014), pp.49 - 57.

[19] Y. Zhang and Y. Zhang, Formation and reduction of acrylamide in Maillard reaction: a review based on the current state of knowledge, Crit. Rev. Food Sci. Nutr., vol. 47, (2007), pp. 521 542.

[20] I. S. Arvanitoyannis and N. Dionisopoulou, Acrylamide: Formation, Occurrence in Food Products, Detection Methods, and Legislation, Crit. Rev. Food Sci. Nutr., vol. 54, (2013), pp. 708-733.
[21] M. F. Cengiz and C. P. B. Gündüz, Acrylamide exposure among Turkish toddlers from selected cereal-based baby food samples, J. Food Chem. Toxicol., vol. 60, (2013), pp. 514-519.

[22] S. Eerola, K. Hollebekkers, A. Hallikainen, and K. Peltonen, Acrylamide levels in Finnish foodstuffs analysed with liquid chromatography tandem mass spectrometry, Mol. Nutr. Food Res., vol. 51, (2007), pp. 239-247.

[23] W. Claeys, B. De Meulenaer, A. Huyghebaert, M. L. Scippo, P. Hoet, and C. Matthys, Reassessment of the acrylamide risk: Belgium as a case-study, Food Control, vol. 59, (2016), pp. 628 635.

[24] European Commission, Commission recommendation of 8 November 2013 on investigations into the levels of acrylamide in foods, Off J Eur Union, vol.301, (2013), pp.15 - 17.

[25] EFSA, "Scientific Opinion acrylamide in Food," EFSA J., vol. 8, (2015), p. 1570.

[26] European Commission, Commission regulation of 20 November 2017 on establishing mititgation measures and benchmark levels for the reduction of the presence of acrylamide in food, Off $\mathrm{J}$ Eur Union, (2017)

[27] E. Capuano, A. Ferrigno, I. Acampa, A. Serpen, ö. Açar, V. Gökmen, V. Fogliano, Effect of flour type on Maillard reaction and acrylamide formation during toasting of bread crisp model systems and mitigation strategies, Food Research International, vol.42, (2009), pp.1295-1302.

[28] M. Przygodzka, M. Piskula, K. Kukurová, Z. Ciesarová, A. Bednarikova, H. Zicliński, Factors influencing acrylamide formation in rye, wheat and spelt breads, Journal of Cereal Science, vol.65, (2015), pp.96-102.

[29] EFSA, Scientific report of EFSA. Results on acrylamide levels in food from monitoring year 2008, EFSA Journal, (2010).

[30] EFSA, Scientific report of EFSA. Results on acrylamide levels in food from monitoring years 2007 - 2009 and exposure assessement, EFSA Journal, (2011).

[31] A. Meghavarnam, S. Janakiraman, Evaluation of acrylamide reduction potential of L-asparaginase from Fusarium Culmorum (ASP-87) in starchy products, LWT-Food Science and Technology, (2017).

[32] T. Wenzl, E. Anklam, European Union database of acrylamide levels in food: update and critical review of data collection, Food Additives and Contaminants, vol. 24, (2007), pp. 5-12.

[33] H. Alyousef, H. Wang, N. Al-Haji, M. Koko, Determination of acrylamide levels in selected commercial and traditional foods in Syria, Tropical Journal of Pharmaceutical Research, vol. 15, (2016), pp. 1275-1281.

[34] E. Norouzi, M. Kamankesh, A. Mohammadi, A, Attaran, Acrylamide in bread samples: determining using ultrasonicassisted extraction and microextraction method followed by gas chromatography-mass spectrometry, Journal of Cereal Science, (2017).

[35] D. Pacetti, E. Gil, N. Frega, L. Álvarez, P. Dueñas, A. Garzón, P. Lucci, Acrylamide levels in selected Colombian foods, Food Additives and Contaminants: Part B, (2015).

[36] C. Gündüz, M. Cengiz, Acrylamide contentes of commonly consumed bread types in turkey, vol.18, (2015), pp.833-841. 